University of Nebraska - Lincoln

DigitalCommons@University of Nebraska - Lincoln

Faculty Publications: Department of Entomology

Entomology, Department of

$10-2020$

\title{
Interplay of phytohormones facilitate sorghum tolerance to aphids
}

\author{
Sajjan Grover \\ University of Nebraska - Lincoln, sgrover2@unl.edu \\ Earl Agpawa \\ University of Nebraska - Lincoln, eagpawa@huskers.unl.edu \\ Gautam Sarath \\ United States Department of Agriculture -Agricultural Research Service, Gautam.sarath@ars.usda.gov \\ Scott E. Sattler \\ University of Nebraska - Lincoln, Scott.Sattler@ars.usda.gov \\ Joe Louis \\ University of Nebraska-Lincoln, joelouis@unl.edu
}

Follow this and additional works at: https://digitalcommons.unl.edu/entomologyfacpub

Part of the Entomology Commons

Grover, Sajjan; Agpawa, Earl; Sarath, Gautam; Sattler, Scott E.; and Louis, Joe, "Interplay of phytohormones facilitate sorghum tolerance to aphids" (2020). Faculty Publications: Department of Entomology. 966. https://digitalcommons.unl.edu/entomologyfacpub/966

This Article is brought to you for free and open access by the Entomology, Department of at DigitalCommons@University of Nebraska - Lincoln. It has been accepted for inclusion in Faculty Publications: Department of Entomology by an authorized administrator of DigitalCommons@University of Nebraska - Lincoln. 


\title{
Interplay of phytohormones facilitate sorghum tolerance to aphids
}

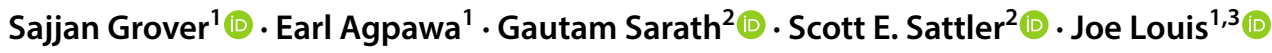

Received: 20 July 2020 / Accepted: 7 October 2020

(c) Springer Nature B.V. 2020

\begin{abstract}
Key message Interactions among phytohormones are essential for providing tolerance of sorghum plants to aphids. Abstract Plant's encounter with insect herbivores trigger defense signaling networks that fine-tune plant resistance to insect pests. Although it is well established that phytohormones contribute to antixenotic- and antibiotic-mediated resistance to insect pests, their role in conditioning plant tolerance, the most durable and promising category of host plant resistance, is largely unknown. Here, we screened a panel of sorghum (Sorghum bicolor) inbred lines to identify and characterize sorghum tolerance to sugarcane aphids (SCA; Melanaphis sacchari Zehntner), a relatively new and devastating pest of sorghum in the United States. Our results suggest that the sorghum genotype SC35, the aphid-tolerant line identified among the sorghum genotypes, displayed minimal plant biomass loss and a robust photosynthetic machinery, despite supporting higher aphid population. Phytohormone analysis revealed significantly higher basal levels of 12-oxo-phytodienoic acid, a precursor in the jasmonic acid biosynthesis pathway, in the sorghum SCA-tolerant SC35 plants. Salicylic acid accumulation appeared as a generalized plant response to aphids in sorghum plants, however, SCA feeding-induced salicylic acid levels were unaltered in the sorghum tolerant genotype. Conversely, basal levels of abscisic acid and aphid feeding-induced cytokinins were accumulated in the SCA-tolerant sorghum genotype. Our findings imply that the aphid-tolerant sorghum genotype tightly controls the relationship among phytohormones, as well as provide significant insights into the underlying mechanisms that contribute to plant tolerance to sap-sucking aphids.
\end{abstract}

Keywords Abscisic acid $\cdot$ Aphids $\cdot$ Cytokinins $\cdot$ OPDA $\cdot$ Phytohormones $\cdot$ Plant tolerance $\cdot$ Sorghum

\section{Introduction}

Sorghum (Sorghum bicolor) is one of the world's most important monocot crops grown for grain and bioenergy and is crucial to our ability to efficiently feed a growing global population. More recently, sorghum has garnered attention as a food crop in Western countries due to its high nutrient content (de Morais Cardoso et al. 2017). However,

Electronic supplementary material The online version of this article (https://doi.org/10.1007/s11103-020-01083-y) contains supplementary material, which is available to authorized users.

Joe Louis

joelouis@unl.edu

1 Department of Entomology, University of Nebraska-Lincoln, Lincoln, NE 68583, USA

2 Wheat, Sorghum, and Forage Research Unit, USDA-ARS, Lincoln, NE 68583, USA

3 Department of Biochemistry, University of Nebraska-Lincoln, Lincoln, NE 68583, USA sorghum is also susceptible to insect pests that can dramatically decrease its yields. Sugarcane aphid (SCA; Melanaphis sacchari Zehntner), a major phloem-feeding insect pest, severely damages the plant by sucking sap from leaves, thereby reducing its photosynthetic ability. In addition, SCA vector plant viruses that result in considerable yield loss (White et al. 2001). While not historically recognized as a serious pest in sorghum, since 2013 SCA has dramatically expanded its range in the United States (Armstrong et al. 2015; Bowling et al. 2016; Nibouche et al. 2018).

Plant tolerance, one among the three categories of plant resistance to insects (Painter 1951; Beck 1965), is considered as the most sustainable, promising, and eco-friendly insect pest management strategy (Panda and Khush 1995; Smith 2005). Despite having knowledge on antixenosis (deters insect settling) and antibiosis (curtails insect population and growth) categories of plant resistance to insects (Smith 2005), we still have limited understanding of tolerance, often referred as "the forgotten child of plant resistance" (Peterson et al. 2017). In addition, mechanisms underlying plant 
tolerance to insect pests are more difficult to establish and as a consequence are poorly understood. However, unlike antixenosis and antibiosis, only plant traits are involved in providing tolerance to insects. Tolerance, therefore, is considered as the plant's ability to maintain its growth and productivity while sustaining similar level of insect pressure as compared to susceptible plants (Smith 2005; Koch et al. 2016). Tolerance also helps in raising the economic injury levels of the plant, thereby exerting less selection pressure on the insects to form new biotypes (Koch et al. 2016; Nalam et al. 2019). Thus, plant tolerance offers great potential for blending into breeding programs or engineering insect-tolerant plants and integrated pest management.

Aphid feeding can manipulate the physiology of host plants (Louis and Shah 2013; Nalam et al. 2019). For example, aphid feeding on a plant alters the rate of photosynthesis, source-sink relationships, nutrient allocation, carbohydrate metabolism, and transport (Moran et al. 2002; Hui et al. 2003; Singh et al. 2011; Machado et al. 2015). Aphid feeding downregulates the photosynthetic efficiency of host plants; however, aphid tolerant plants have the ability for photosynthetic recovery as compared to susceptible plants (Smith 2005; Koch et al. 2016). Furthermore, upon aphid feeding, plants tend to have an oxidative burst that can lead to the production of excessive reactive oxygen species (ROS), and if not efficiently removed, the ROS can eventually lead to the death of plant cells and cellular components (Foyer and Noctor 2005; Kotchoni and Gachomo 2006; Liu et al. 2010; Kerchev et al. 2012). However, aphid tolerant plants have the ability to bypass the negative impacts associated with plant defenses and invest towards increased photosynthesis to maintain plant growth and sustained high insect pressure as compared to non-tolerant and susceptible plants.

Phytohormones are not only crucial for plant development, but are also involved in mediating plant responses to stress (Verma et al. 2016). Aphid feeding on host plants are known to induce several plant defense signaling pathways (Erb et al. 2012; Louis and Shah 2013; Nalam et al. 2019). Plants recognize the aphid effectors and/or elicitors present in saliva or honey dew and induce the plant signaling cascades (Nalam et al. 2019). Many of these signaling cascades respond to changes in hormone levels. Among various phytohormones, salicylic acid (SA) and jasmonic acid (JA) are mainly involved in modulating plant defense responses to aphid and pathogen attack (Erb et al. 2012; Zhang et al. 2020). For example, expression of genes involved in SA pathway were upregulated in sorghum resistant plants infested with SCA (Kiani and Szczepaniec 2018). SA induction may lead to hypersensitive response and systemic acquired responses and lead to synthesis of pathogenesis related proteins ( $\mathrm{Li}$ et al. 2019). In addition to SA, JA acts as a key player in providing sorghum resistance to greenbug aphids (Schizaphis graminum) (Zhu-Salzman et al. 2004).
It was previously reported that the exogenous application of methyl jasmonate (MeJA) provided enhanced resistance to greenbug aphids in sorghum (Zhu-Salzman et al. 2004). However, the role of phytohormones and how they intersect to provide compensatory routes to sorghum tolerance to aphids are poorly understood.

Although a few studies have demonstrated the role of sorghum resistance to sap-sucking aphids (Zhu-Salzman et al. 2004; Kiani and Szczepaniec 2018; Tetreault et al. 2019), the extent of natural variation and tolerance mechanisms in sorghum against phloem-feeding aphids, such as SCA, remains largely unknown and unexplored. In this study, we utilized the founder lines from the recently developed sorghum nested association mapping (NAM) population (Bouchet et al. 2017) to understand the mechanisms of sorghum tolerance to SCA. Tolerance screening experiments identified SC35 as the most tolerant sorghum genotype to SCA among the NAM founder lines. Aphid counts were higher on SC35 after 14 days of SCA infestation, while having lesser impact on plant growth parameters compared to other sorghum genotypes. Phytohormone analysis revealed significantly higher basal levels of 12-oxo-phytodienoic acid (OPDA) in SC35 genotype compared to RTx430 and SCAsusceptible SC1345 plants. Furthermore, our results indicate that basal levels of abscisic acid (ABA) and aphid feedinginduced cytokinins (CKs), particularly trans-zeatin riboside (tZR), may contribute to enhanced photosynthesis and plant growth, and consequently plant tolerance to aphids. Thus, from this study, we conclude that the interplay among phytohormones is essential for providing tolerance of sorghum plants to aphids.

\section{Materials and methods}

\section{Plant material}

The sorghum founder NAM population were obtained from USDA-GRIN global germplasm (USA). These lines include Ajabsido, Macia, P898012, SC35, SC265, SC283, SC971, SC1103, SC1345, and Segaolane, along with the reference line RTx 430 . The seeds for these lines were further produced in University of Nebraska-Lincoln (UNL) greenhouse. For experiments, sorghum plants were grown in pots filled with soil mixed with vermiculite and perlite (PRO-MIX BX BIOFUNGICIDE + MYCORRHIZAE, Premier Tech Horticulture Ltd., Canada) at the UNL greenhouse with a 16-h-light/8-h-dark photoperiod, $25^{\circ} \mathrm{C}$, and 50-60\% relative humidity. Plants were watered regularly and fertilized once a week. Two-week-old plants at the three-leaf stage (Vanderlip and Reeves 1972) were used for all the experiments. All experiments were performed in same conditions in which the plants were grown. 


\section{Insect colony}

The SCA were reared as previously described (Tetreault et al. 2019) and was maintained on the SCA susceptible BCK60 sorghum genotype in a growth chamber with 16-h-light/8-h-dark photoperiod, $140 \mu \mathrm{E} \mathrm{m}^{-2} \mathrm{~s}^{-1}$ light quality, $23{ }^{\circ} \mathrm{C}$, and $50-60 \%$ relative humidity. The BCK60 sorghum plants for aphid rearing were grown in the greenhouse until it reached 7-leaf stage. New plants were replaced with old, degenerated plants in growth chamber, whenever needed. For all the experiments, adult aphids were used.

\section{Tolerance experiment}

The tolerance to SCA experiment was performed against ten NAM parent lines, along with RTx430. For each genotype, there were 12 uninfested (control) and 12 aphid-infested plants. Ten adult apterous SCA of similar age and condition were released on each plant and covered with tubular clear plastic cages $(24$ in $\times 1.6$ in; length $\times$ diameter $)$ ventilated with organdy fabric on the sides and top of the cage for proper aeration. Uninfested plants were also covered with cages. The experimental design was Completely Randomized Design (CRD), i.e., all plants including SCAinfested and uninfested, were randomly arranged. The experiment was terminated until the one of the NAM line was dead because of SCA feeding. More than $70 \%$ of the most susceptible genotype (SC1345) was dead after 14 days of SCA infestation. Therefore, at day 14, total number of aphids, including both adults and nymphs were counted on each plant. The leaf area showing discoloration was considered for injury rating on the scale of $1-5$ as described previously (Tetreault et al. 2019). The plant growth parameters presented in Table 1 and Supp. Fig. S2 were calculated as described previously (Voothuluru et al. 2006; Armstrong et al. 2018).

\section{Chlorophyll fluorescence, photosynthesis, and gas-exchange measurements}

Photosynthetic responses of RTx430, SCA-tolerant (SC35), susceptible (SC1345) sorghum plants were recorded at 12 dpi of SCA using a portable photosynthesis system (model LI-6800, LI-COR Biosciences, Lincoln, NE) in controlledenvironment growth chamber. The newest fully expanded leaf was used to take reading and the area of each leaf was measured, and values were entered manually into the system. The clamped leaf was allowed to stabilize for approximately $20 \mathrm{~min}$ at reference $\mathrm{CO}_{2}$ levels. Reference $\mathrm{CO}_{2}$ level was maintained at $400 \mu \mathrm{mol} \mathrm{mol}{ }^{-1}$, flow rate was set at $500 \mu \mathrm{mol} \mathrm{s}^{-1}$, relative humidity at $50 \%$ and light intensity at $1000 \mu \mathrm{mol} \mathrm{m} \mathrm{m}^{-2} \mathrm{~s}^{-1}$. The maximum quantum efficiency of PSII, $\frac{F v^{\prime}}{F m^{\prime}}$, was calculated using the equation:

$\frac{F v^{\prime}}{F m^{\prime}}=\frac{F m^{\prime}-F o^{\prime}}{F m^{\prime}}$

Photochemical quenching was calculated using the equation:

$\frac{F m^{\prime}-F s^{\prime}}{F m^{\prime}-F O^{\prime}}$

where $F v^{\prime}$ refers to variable fluorescence, $F m^{\prime}$ is maximal fluorescence, $F o^{\prime}$ is minimum fluorescence, and $F s^{\prime}$ is the steady-state fluorescence.

Electron transfer rate (ETR) was calculated using the equation:

Table 1 Plant growth parameters of sorghum genotypes after sugarcane aphid infestation for 14 days

\begin{tabular}{lcccc}
\hline Sorghum genotypes & Height loss $(\mathrm{cm})$ & Leaf biomass loss $(\%)$ & Root biomass loss $(\%)$ & Leaf count loss $(\#)$ \\
\hline RTx430 & $16.87 \pm 2.24 \mathrm{~cd}$ & $63.64 \pm 2.83 \mathrm{de}$ & $61.23 \pm 3.23 \mathrm{e}$ & $1.33 \pm 0.21 \mathrm{f}$ \\
Ajabsido & $13.42 \pm 1.55 \mathrm{~cd}$ & $62.64 \pm 4.34 \mathrm{de}$ & $63.15 \pm 4.42 \mathrm{de}$ & $2.25 \pm 0.18 \mathrm{de}$ \\
Macia & $31.96 \pm 4.43 \mathrm{~b}$ & $77.44 \pm 4.22 \mathrm{bc}$ & $81.06 \pm 2.19 \mathrm{ab}$ & $3.83 \pm 0.42 \mathrm{~b}$ \\
P898012 & $21.54 \pm 1.60 \mathrm{c}$ & $65.64 \pm 2.29 \mathrm{de}$ & $71.39 \pm 3.33 \mathrm{~cd}$ & $2.17 \pm 0.23 \mathrm{e}$ \\
SC1103 & $12.61 \pm 1.44 \mathrm{~d}$ & $49.79 \pm 3.49 \mathrm{f}$ & $61.45 \pm 1.99 \mathrm{e}$ & $3.00 \pm 0.21 \mathrm{~cd}$ \\
SC1345 & $37.67 \pm 4.86 \mathrm{ab}$ & $92.87 \pm 2.60 \mathrm{a}$ & $83.07 \pm 2.32 \mathrm{ab}$ & $5.00 \pm 0.00 \mathrm{a}$ \\
SC265 & $16.78 \pm 1.33 \mathrm{~cd}$ & $57.88 \pm 2.91 \mathrm{ef}$ & $66.81 \pm 4.42 \mathrm{de}$ & $1.25 \pm 0.13 \mathrm{f}$ \\
SC283 & $21.75 \pm 3.98 \mathrm{c}$ & $69.2 \pm 3.63 \mathrm{~cd}$ & $59.38 \pm 5.35 \mathrm{e}$ & $2.58 \pm 0.43 \mathrm{de}$ \\
SC35 & $8.57 \pm 1.43 \mathrm{~d}$ & $32.44 \pm 2.90 \mathrm{~g}$ & $45.19 \pm 2.98 \mathrm{f}$ & $0.83 \pm 0.11 \mathrm{f}$ \\
SC971 & $31.65 \pm 5.16 \mathrm{~b}$ & $68.59 \pm 3.39 \mathrm{~cd}$ & $78.72 \pm 3.05 \mathrm{bc}$ & $3.5 \pm 0.48 \mathrm{bc}$ \\
Segaolane & $45.24 \pm 2.29 \mathrm{a}$ & $85.71 \pm 3.05 \mathrm{ab}$ & $88.59 \pm 2.31 \mathrm{a}$ & $4.08 \pm 0.36 \mathrm{~b}$ \\
\hline
\end{tabular}

Two-week-old sorghum NAM founder lines were initially infested with 10 adult apterous aphids per plant and various plant growth parameters monitored after 14 days post infestation. Uninfested plants of similar age were used as controls to calculate changes in plant growth upon aphid infestation. Negative binomial distribution was used to analyze leaf count data. Different letters indicate significant difference relative to each other $(P<0.05$; Tukey's test). Values in table represent mean $\pm \operatorname{SE}(n=12)$ 


$$
E T R=\frac{F v^{\prime}}{F m^{\prime}} * i * \alpha * \beta
$$

where $\alpha, i$, and $\beta$ are leaf absorbance, incident actinic light intensity, and the fraction of absorbed light partitioned to PSII versus PSI, respectively.

\section{Phytohormone quantification}

For the plant hormone measurements (OPDA, JA, JA-Ile, SA, IAA, IAA-Asp, ABA, tZR and cZR), samples from SCA-tolerant (SC35), susceptible (SC1345) and the reference line (RTx430) were collected. Approximately $100 \mathrm{mg}$ leaf tissue from control and infested samples at 7 and 14 dpi from each genotype were collected and flash frozen immediately. We were not able to collect plant tissues from susceptible plants, because the plants were dead at day 14. There were three to five replications for each treatment. LC-MS assay and quantification of plant hormones were performed at the Proteomics and Metabolomics Facility at the Center for Biotechnology, UNL using deuterium-labeled internal standards as previously described (Chapman et al. 2018; Varsani et al. 2019).

\section{Statistical analyses}

The statistical analyses were performed using a generalized mixed model analysis (PROC GLIMMIX) in SAS 9.4 (SAS Institute). Plants for tolerance experiment were arranged in a completely randomized design with 12 replicates/sorghum genotype. Negative binomial distribution was used to analyze the count data. Pairwise comparisons between treatments or genotypes were performed by comparing the means using Tukey's honestly significant difference tests $(P<0.05)$.

\section{Results}

\section{Sorghum genotype SC35 displayed tolerance to SCA}

A panel of ten sorghum NAM founder lines, which represent the global genetic diversity of sorghum inbred lines along with an elite reference line RTx430 to which each NAM founder line was crossed to generate the recombinant inbred lines (Bouchet et al. 2017), were screened for aphid tolerance. We initially monitored aphid numbers and plant damage ratings (Tetreault et al. 2019) between control and SCA-infested plants, which had supported comparable and/ or higher number of aphids relative to RTx430 plants. Aphid counts and plant growth parameters on sorghum NAM population were measured at 14 days post infestation (dpi) of SCA, because at this time point the susceptible SC1345 of the NAM founder lines was dead (Fig. 1a). Here, we found that the SC1345 genotype had an injury rating of more than 5 and $>70 \%$ plants were dead from SCA feeding by $14 \mathrm{dpi}$ (Fig. 1a). In addition, the number of aphids at 7 dpi of SCA were significantly higher on SC35 and SC1345 plants compared to RTx430 plants (Supp. Fig. S1), however, the susceptible SC1345 plants were dead by $14 \mathrm{dpi}$ as a result of SCA feeding (Fig. 1a). Consequently, no live aphids were found on SCA-susceptible sorghum SC1345 plants after 14 dpi. Significantly higher number of aphids were found on Ajabsido, SC1103 and SC35 compared to RTx430, while the number of aphids present on P898012 and SC283 was comparable to RTx430 plants (Fig. 1a). Supp. Table S1 shows the mean number of SCA on different sorghum NAM founder lines after $14 \mathrm{dpi}$. Damage rating data indicated that SC35 had minimal injury compared to other lines except SC1103 plants (Fig. 1a). The percent plant biomass loss (dry weight) indicated that SC35 genotype had least biomass loss, followed by SC1103 after SCA infestation (Supp. Fig. S2). Infested SC1345 plants had lost 90\% plant biomass by 14 dpi. Loss of leaves was also significantly lower in SC35, whereas SC35 and SC1103 plants exhibited similar reduction in plant height (Table 1). The plant growth parameters of all sorghum genotypes with and without SCA infestation for 14 days is shown in Supp. Table S2. Overall, SC35 was able to sustain highest aphid pressure, while maintaining minimal plant biomass loss among all the sorghum genotypes tested. Moreover, a principal component analysis (PCA) comparing the impact of aphid infestation on plant growth after 14 days of SCA infestation (components 1 and 2 explained $76 \%$ of the variance) indicated that the SC35 genotype clustered separately and farthest from other sorghum NAM founder lines (Fig. 1b, Supp. Fig. S3). The aphid count contributed to negative PC1, thereby leading to SC35 cluster separation in PCA (Supp. Fig. S3). These results collectively suggest that the sorghum genotype SC35 displayed tolerance to SCA among all the NAM founder lines.

\section{Sorghum SC35 genotype has improved photosynthetic machinery despite supporting higher aphid population}

To determine the sorghum physiological responses to SCA infestation, we measured photosynthetic and transpiration rates, stomatal conductance, intercellular $\mathrm{CO}_{2}$ concentration, electron transfer rate, maximum quantum efficiency of photosystem II (PSII), and photochemical quenching on RTx430, SC1345 and SC35 plants. The measurements were taken after 12 days of SCA infestation, because all the susceptible plants were dead after 14 days of SCA infestation. Our results indicated that the basal photosynthetic rates were similar in RTx430, SC1345 and SC35 sorghum plants (Fig. 2a). SCA infestation reduced photosynthesis in all three genotypes, however the extent to which it decreased 
Fig. 1 Sorghum genotype SC35 exhibit tolerance to sugarcane aphids (SCA). a Total number of sugarcane aphids (left Y-axis) recovered 14 days after aphid infestation of 2-weekold sorghum plants that were initially infested with 10 adult apterous aphids per plant and damage scores (right Y-axis) (scale: 0-5) for each sorghum NAM founder line after 14 days of aphid infestation $(n=12)$. Negative binomial distribution was used to analyze aphid count data. Alphabets with the same letter in the same case are not significantly different from each other $(P<0.05$; Tukey's test). Lowercase letters shows statistics for damage ratings and uppercase for aphid counts. Error bars represent mean \pm SE. Tolerance evaluation experiment was replicated two times with at least 12 sorghum plants/genotype. b Principal component analysis (PCA) of data collected from tolerance experiment on sorghum NAM founder lines after 14 days of SCA infestation. Uninfested plants of similar age were used to calculate changes in plant growth upon aphid infestation

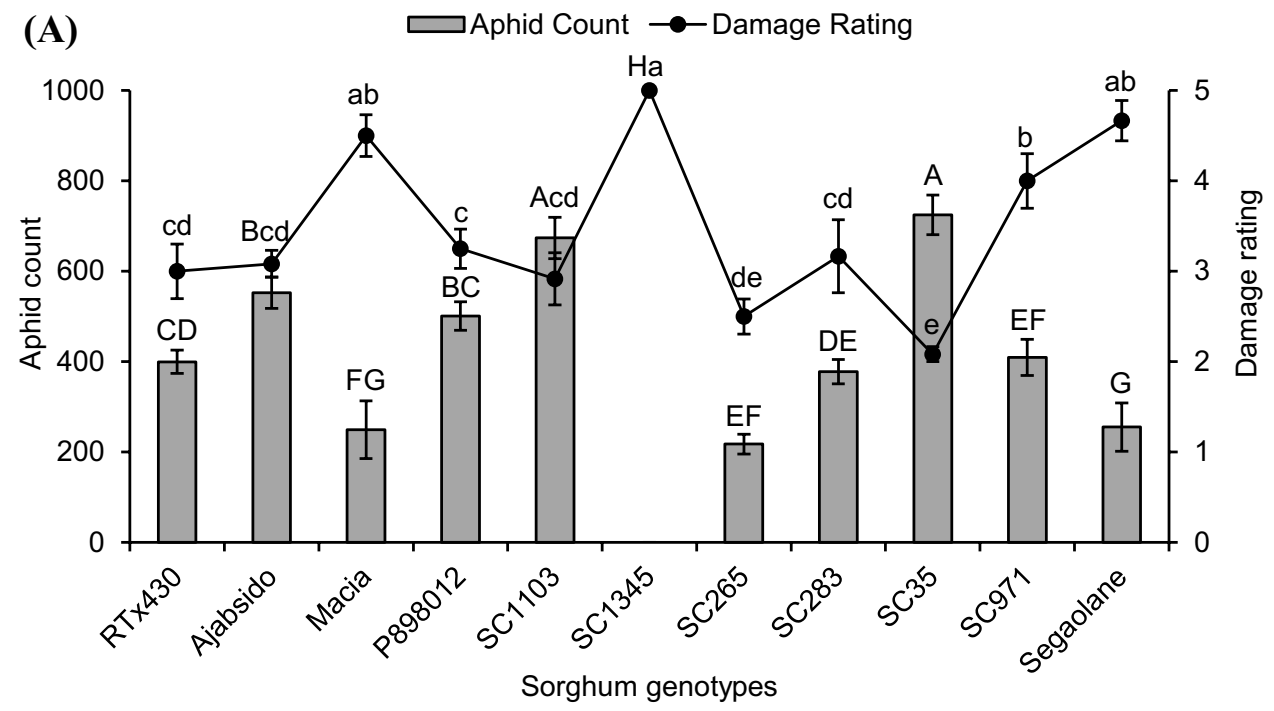

(B)

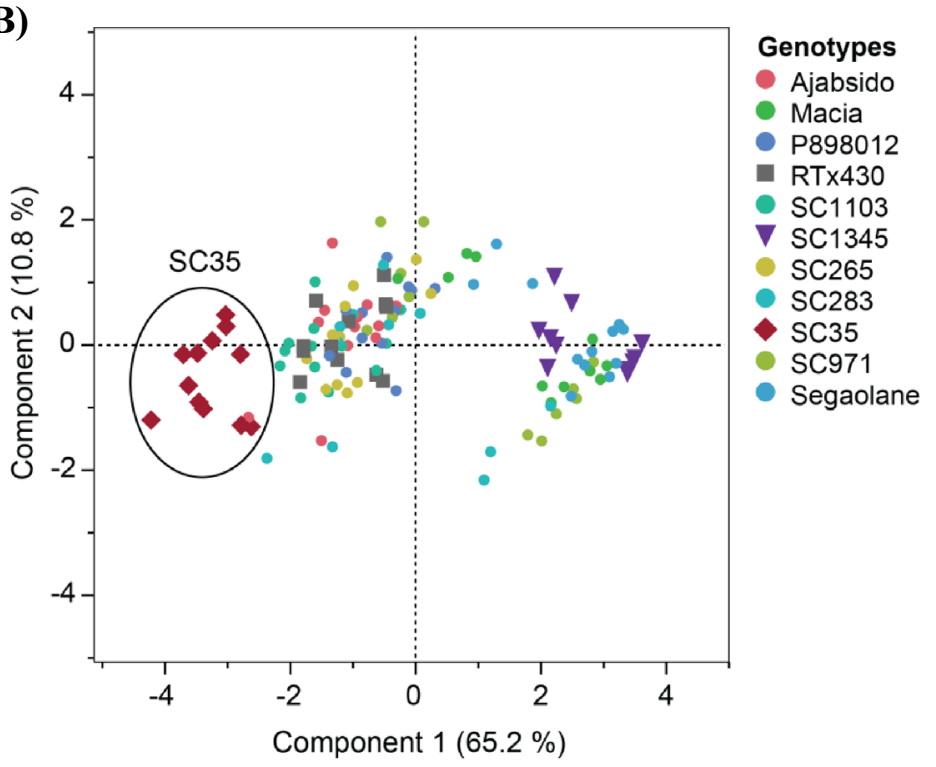

was less in RTx430 and SC35 as compared to SC1345 plants (Fig. 2a). No significant differences in the transpiration rate and stomatal conductance were observed in RTx430 and SC35 plants after SCA infestation, however, both parameters were significantly decreased in SC1345 plants (Fig. 2b, c). A similar pattern was observed for other photosyntheticrelated parameters such as electron transfer rate, maximum quantum efficiency of PSII and photochemical quenching (Fig. 2d-f). These data indicated that the tolerant genotype SC35 had the ability to maintain enhanced photosynthesis despite supporting higher aphid population. Intercellular $\mathrm{CO}_{2}$ concentration, which represents the efficiency/ability of $\mathrm{CO}_{2}$ utilization by plants for photosynthesis, did not exhibit any significant difference before or after SCA infestation in the SC35 genotype. In contrast, there was drastic increase in intercellular $\mathrm{CO}_{2}$ concentration in $\mathrm{RT} \times 430$ and
SC1345 plants upon SCA infestation, suggesting a reduction in the photosynthetic activity (Fig. 2g). Although there were 1.8 times higher number of aphids on SC35 compared to RTx430 plants, SC35 genotype displayed several physiological and photosynthetic parameters similar to RTx430 plants (Fig. 2), clearly demonstrating its ability to maintain a robust photosynthetic machinery.

\section{SC35 had higher constitutive levels of OPDA}

Phytohormones are important regulators of plant resistance and often influence the extent of insect colonization on host plants (Howe and Jander 2008; Louis and Shah 2013; Nalam et al. 2019). Interplay of several hormonal pathways, including but not limited to SA, JA and ABA signaling, determine the success of insect colonization on plants. To assess the 
$\square$ Uninfested

(A)

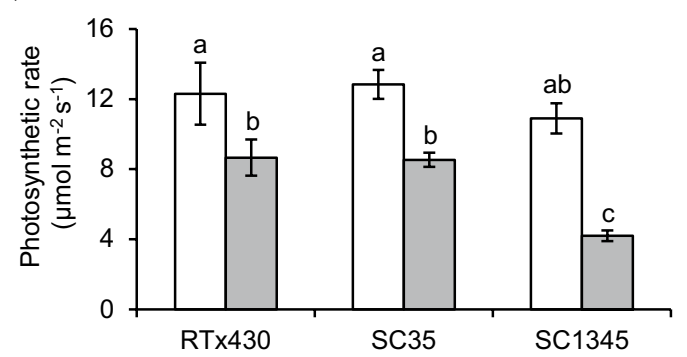

(B)

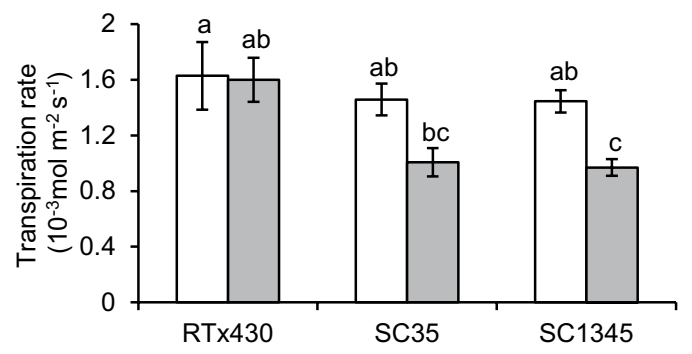

(C)

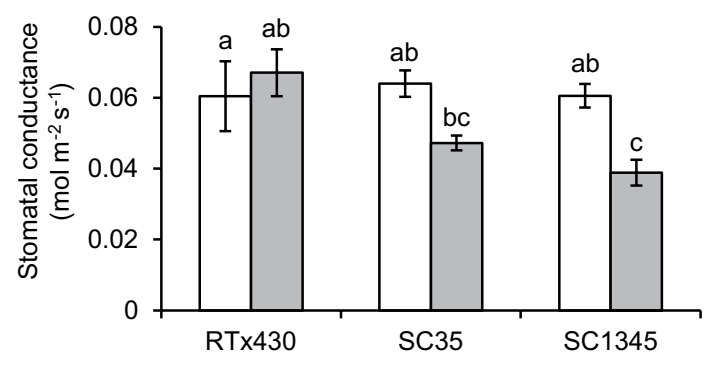

$\square$ Aphid infested

(D)

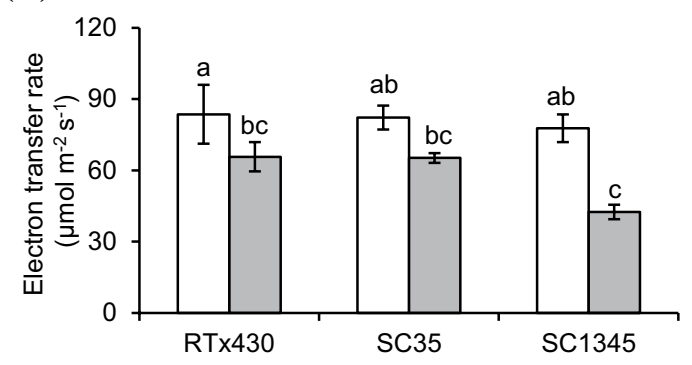

(E)

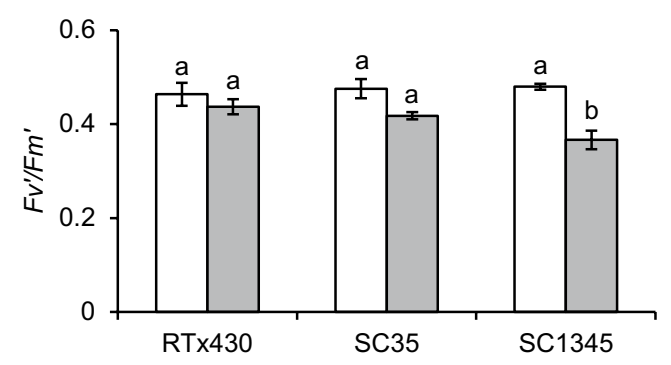

(F)

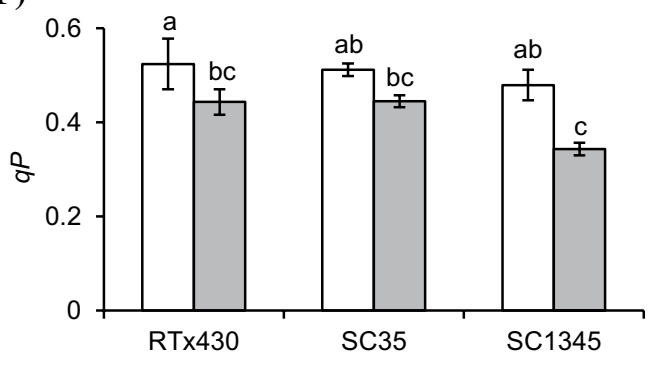

(G)

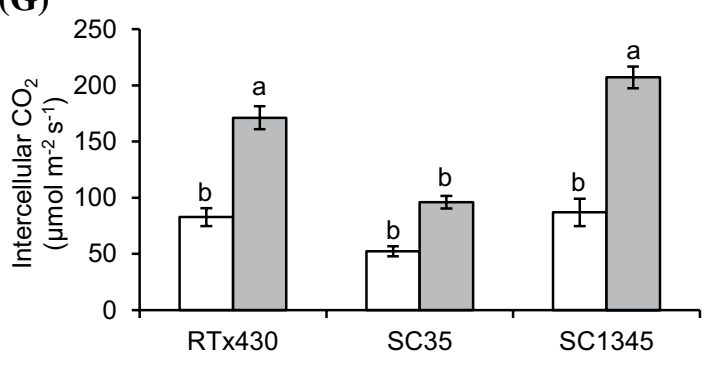

Fig. 2 Sorghum SC35 genotype has improved photosynthetic machinery. Gas exchange and chlorophyll fluorescence parameters in RTx430, SC35 and SC1345 plants with and without sugarcane aphid (SCA) infestation for 12 days. a Photosynthetic rate b transpiration

role of phytohormones in sorghum tolerance to SCA, first, we quantified the levels of JA, OPDA, a precursor of JA biosynthesis, and JA-isoleucine (JA-Ile), the biologically active form of JA. As mentioned above, since the susceptible plants (SC1345) were dead after 14 days of SCA infestation, we were not able to collect SC1345 tissues for the 14th day rate $\mathbf{c}$ stomatal conductance, $\mathbf{d}$ electron transfer rate $\mathbf{e} F v^{\prime} / F m^{\prime}, \mathbf{f}$ photochemical quenching $(q P)$, and $\mathbf{g}$ intercellular $\mathrm{CO}_{2}$ concentration. $(n=3-5)$. Different letters indicate significant differences among genotypes $(P<0.05$; Tukey's test). Error bars represent mean $\pm \mathrm{SE}$

hormonal analysis. Our results shown that SC35 exhibited significantly elevated levels of OPDA on day 7 compared to RTx430 and SC1345 plants, regardless of SCA infestation (Fig. 3a). On day 14, SCA-uninfested SC35 plants also showed significantly higher levels of OPDA, but SCA infestation suppressed the levels of OPDA and was comparable to 


\section{$\square R \operatorname{RT} 430 \quad \square \mathrm{SC} 35 \quad \square \mathrm{SC} 1345$}

(A)

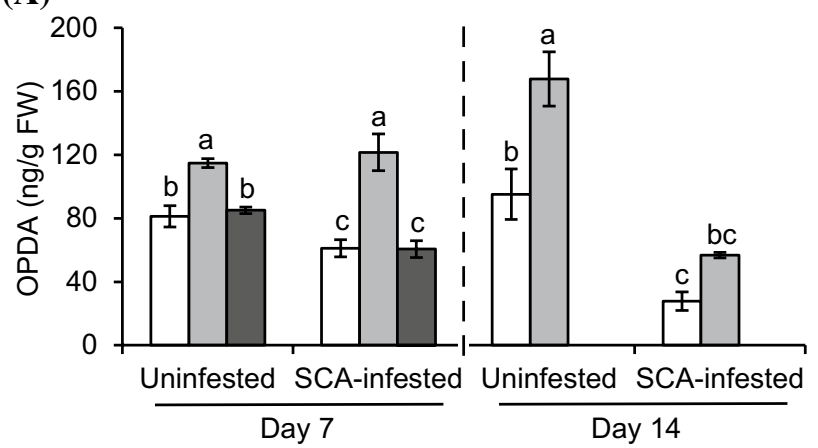

(B)

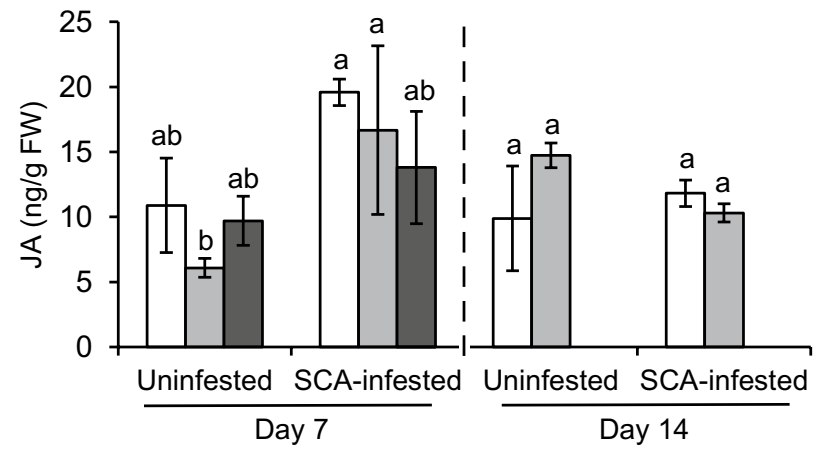

Fig. 3 Levels of a 12-Oxo-phytodienoic acid (OPDA), b jasmonic acid (JA), c JA-isoleucine (JA-Ile), and d salicylic acid (SA) in RTx430, SC35 and SC1345 plants with and without sugarcane aphid

the RTx430 plants. Basal JA levels were comparable among all genotypes (Fig. 3b). Although SCA feeding significantly increased JA levels in SC35 plants compared to SC35 uninfested plants, the levels were comparable among all three genotypes after SCA infestation for 7 days (Fig. 3b). We did not find any significant difference in the levels of JA with and without SCA infestation on RTx430 and SC35 plants after 14 dpi (Fig. 3b). Similarly, no significant differences were found in the levels of JA-Ile in all three genotypes on day 7 with or without SCA infestation, however on day 14, SCA infestation diminished JA-Ile levels in SC35 plants (Fig. 3c).

\section{SCA feeding did not alter salicylic acid levels in the sorghum tolerant genotype}

Previously, it was shown that SA is involved in plant defense signaling and provides enhanced resistance to sap-sucking insects (Louis and Shah 2013; Züst and Agrawal 2016). When we monitored the levels of SA there was no significant difference in the basal levels among the three genotypes (Fig. 3d). SCA feeding triggered the accumulation of SA in RTx430 and SC1345 plants after 7 days of aphid infestation.
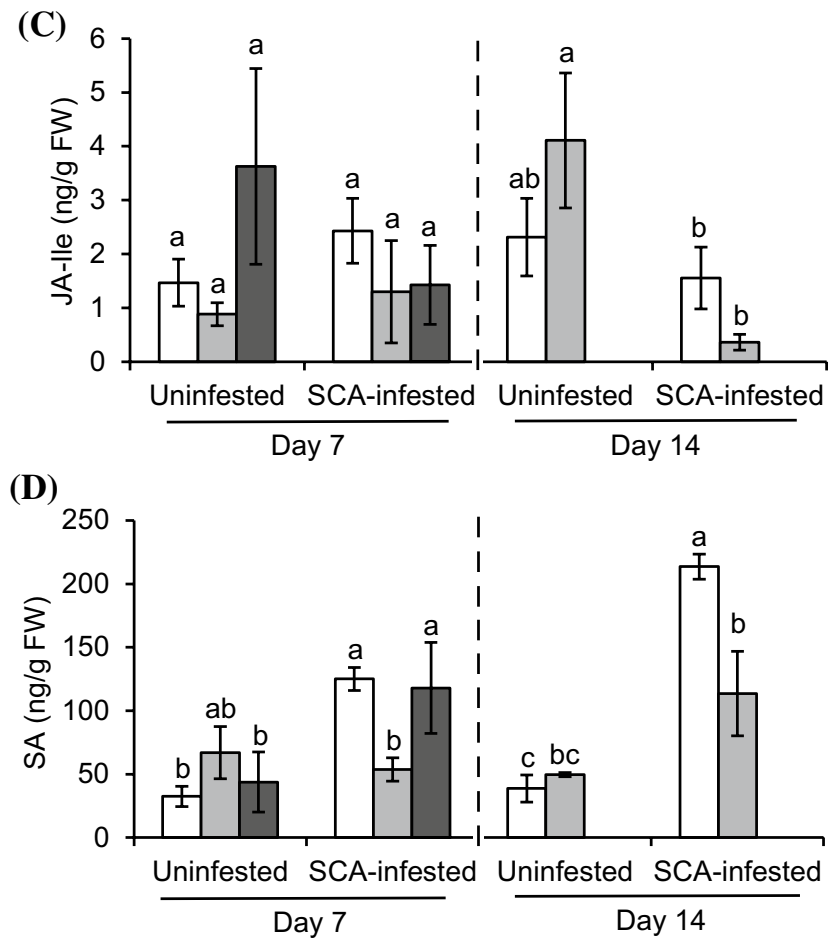

(SCA) infestation for 7 and 14 days. $(n=3-5)$. FW, fresh weight. Different letters indicate significant differences among genotypes at that particular day $(P<0.05$; Tukey's test). Error bars represent mean $\pm \mathrm{SE}$

Similarly, in RTx430, SA levels increased approximately fourfold after SCA-infestation for 14 days. Despite having higher number of aphids (Fig. 1; Supp. Fig. S1), SCA feeding did not alter SA levels on SC35 plants compared to SCAuninfested SC35 plants after 7 and 14 dpi (Fig. 3d).

\section{SCA feeding altered the levels of auxin and CKs, but not $A B A$, in the sorghum tolerant genotype}

Auxin/indole-3-acetic acid (IAA) is involved in various aspects of plant growth and development (Gallei et al. 2020), and it was reported that gall-inducing insects enhance IAA accumulation in host plants (Mapes and Davies 2001; Tooker and De Moraes 2011). IAA levels were comparable among all genotypes with and without aphid infestation after 7 dpi (Fig. 4a). Basal IAA levels were significantly higher in 14 day SC35 control plants, however, SCA feeding significantly reduced IAA levels in SC35 plants compared to SCA-uninfested SC35 plants and was comparable to RTx430 plants (Fig. 4a). The conjugated form of auxin, IAA-Aspartic acid (Asp), promotes plant disease development and enhances pathogen progression in host plants (González-Lamothe et al. 2012). No 
$\square R \operatorname{Rx} 430 \quad \square \mathrm{SC} 35 \quad \square \mathrm{SC} 1345$
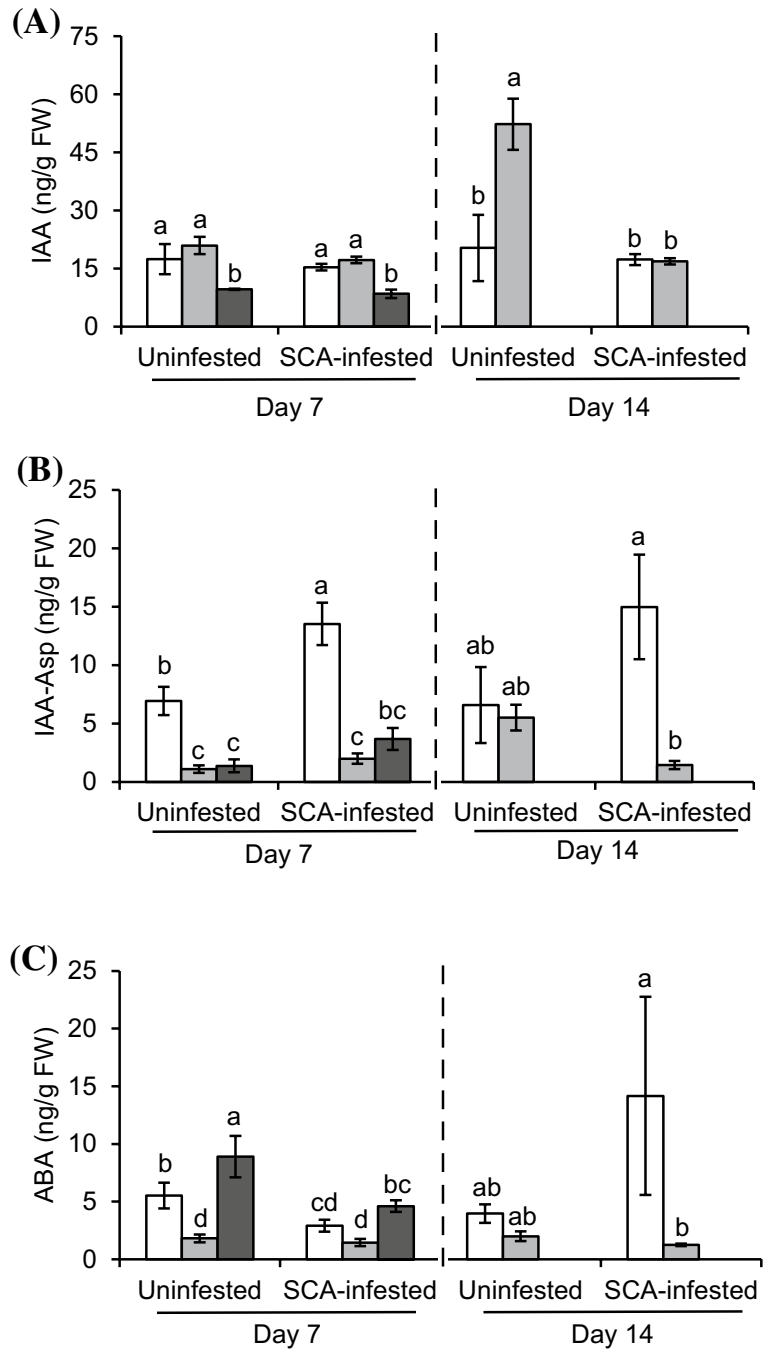

Fig. 4 Levels of a indole-3-acetic acid (IAA), b IAA-Aspartic acid (IAA-Asp), and $\mathbf{c}$ abscisic acid (ABA) in RTx430, SC35 and SC1345 plants with and without sugarcane aphid (SCA) infestation for 7 and 14 days. $(n=3-5)$. FW, fresh weight. Different letters indicate significant differences among genotypes at that particular day $(P<0.05$; Tukey's test). Error bars represent mean $\pm \mathrm{SE}$

significant changes were found in the levels of IAA-Asp in the SC35 genotype with and without aphid infestation after 7 and $14 \mathrm{dpi}$, indicating that IAA-Asp may not be a key hormone in providing sorghum tolerance to SCA (Fig. 4b). Levels of ABA, which is required for aphid colonization on host plants (Studham and MacIntosh 2012; Hillwig et al. 2016; Chapman et al. 2018), were significantly higher in the aphid uninfested and aphid-infested susceptible SC1345 genotype after 7 days (Fig. 4c). However, there were no significant changes in the ABA levels in the sorghum tolerant genotype with and without SCA infestation after 7 and 14 days (Fig. 4c).
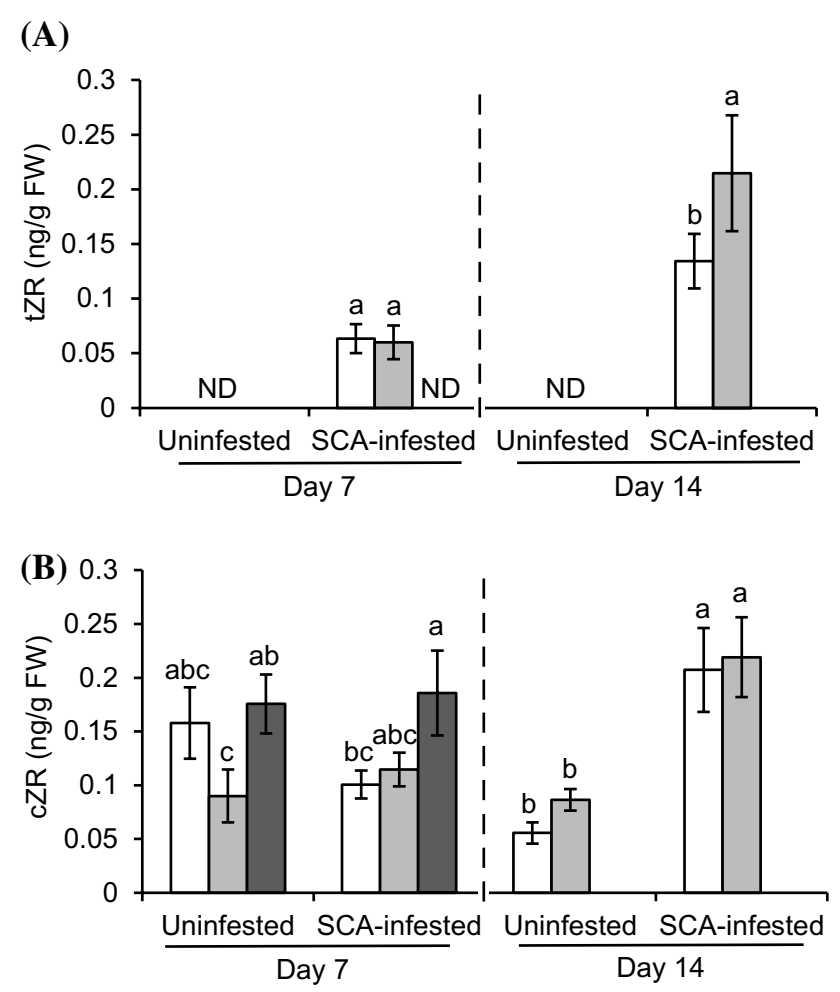

Fig. 5 Levels of $\mathbf{a}$ trans-zeatin riboside (tZR) and $\mathbf{b}$ cis-zeatin riboside (cZR) in RTx430, SC35 and SC1345 plants with and without sugarcane aphid (SCA) infestation for 7 and 14 days. $(n=3-5)$. FW, fresh weight; ND, not detected. Different letters indicate significant differences among genotypes at that particular day $(P<0.05$; Tukey's test). Error bars represent mean $\pm \mathrm{SE}$

Next, we measured the levels of CKs with and without SCA infestation. The most common CK in higher plants is zeatin, and the active form is tZR (Großkinsky et al. 2013). Levels of tZR were undetectable in all three sorghum genotypes that were uninfested with aphids (Fig. 5a). However, SCA feeding for 7 days induced comparable levels of tZR in RTx430 and SC35 plants and the levels were significantly higher in SC35 plants compared to RTx430 plants after 14 days of infestation (Fig. 5a). Interestingly, tZR levels were not detectable in SCA-fed susceptible plants after 7 days. We also measured cis-zeatin riboside (cZR), which is generally considered as non-active compared to tZR (Großkinsky et al. 2013). There was no significant difference in the levels of cZR among the three genotypes after 7 days of SCA infestation (Fig. 5b). However, SCA feeding significantly increased cZR levels in both RTx430 and SC35 plants after 14 dpi compared to SCA-uninfested plants (Fig. 5b). 


\section{Discussion}

Here, we demonstrate that phytohormones play a key role in providing tolerance to sap-sucking aphids. While it is known that plant hormones contribute to antixenoticand antibiotic-mediated resistance to insect pests, to our knowledge, this is the first study that addresses the tolerance mechanisms and its relationship to phytohormones in providing plant tolerance to aphids. Based on our results, we propose that the sorghum SCA-tolerant genotype exploits the interplay of phytohormones that facilitate enhanced plant growth and development.

Phytohormonal biosynthesis occur in various plant compartments. For example, OPDA, a precursor in JA pathway is synthesized in chloroplast and further transported to peroxisome for JA biosynthesis (Wasternack and Strnad 2018). The apparent lack of elevated levels of JA accumulation due to constitutive higher OPDA levels in SC35 genotype (Fig. 3) suggest the possibility of OPDA having an additional role, independent of the JA pathway. In fact, OPDA was shown to regulate maize defense mechanisms against the corn leaf aphid that is not dependent on the JA pathway (Varsani et al. 2019; Grover et al. 2020). Chloroplast is the site for photosynthesis in plants. It is highly plausible that constitutive OPDA levels in the SC35 genotype contribute towards improved photosynthesis during aphid infestation relative to other lines tested. Indeed, we did not find any significant differences in electron transport rate, photochemical quenching and maximum quantum efficiency of PSII despite heavy SCA infestations on SC35 genotype compared to the SCAinfested RTx430 plants (Fig. 2). In Arabidopsis, cyclophilin CYP20-3, which is present in the chloroplast, was found to be a receptor of OPDA (Kopriva 2013). CYP20-3 acts as an interface between plant growth and defense by binding with serine acetyltransferase 1 (SAT1), thioredoxins (Trxs) and 2-Cys peroxiredoxin (2-CysPrxs), which are important for the activation of enzymes involved in Calvin cycle, redox homeostasis, and downstream signaling via glutathione (Barbosa dos Santos and Park 2019). Thus, it is possible that OPDA synthesized in the chloroplast acts synergistically with other factors, for example CYP20-3, to enhance photosynthesis in the SCA-tolerant sorghum genotype, which is an important determinant for optimal plant growth and development.

Our earlier work (Chapman et al. 2018) demonstrated that JA and ABA contribute to soybean tolerance to soybean aphids. The role of former hormone in sorghum tolerance to aphids is not supported by the observation that sorghum SCA-tolerant genotype had similar levels of JA and JA-Ile compared to SCA-susceptible and RTx430 plants (Fig. 3b, c). ABA is reported to promote aphid colonization on host plants (Studham and MacIntosh 2012; Hillwig et al. 2016; Chapman et al. 2018). Consistent with previous studies, we have also observed that susceptible sorghum plants had higher ABA accumulation compared to sorghum tolerant genotype (Fig. 4c). Although ABA is one of the major factors that promotes aphid colonization on host plants (Studham and MacIntosh 2012; Hillwig et al. 2016; Chapman et al. 2018), our observation of no significant changes in ABA levels before or after SCA infestation in SCA-tolerant sorghum genotype (Fig. 4c) suggests that the patterns reported here reflect the plant's ability to utilize basal ABA levels to promote sorghum tolerance to aphids. Importantly, basal levels of ABA are reported to be crucial for maintaining plant growth and development (Yoshida et al. 2019). More recently, it was shown that Arabidopsis basal ABA levels may enhance plant biomass under non-stressed conditions by interfering with a "stress-escape" response (Negin et al. 2019). Taken together, these data would strongly support our findings for a tight linkage between hormonal levels and regulation as a key part of the plant tolerance response.

Aphid feeding on host plants is reported to activate SAmediated resistance pathways (Louis and Shah 2013; Züst and Agrawal 2016). In fact, we have observed an increase in SA levels in both RTx430 and SC1345 plants after SCA infestation (Fig. 3d). Here, despite having a significant increase in aphid numbers on the sorghum tolerant SC35 genotype, there were no obvious changes in SA levels before or after SCA infestation. Our results support the concept that elevated SA levels suppress plant growth and development (van Butselaar and Van den Ackerveken 2020), and not activating the SA pathway after aphid infestation may be a mechanism generally utilized by aphid-tolerant plants to circumvent the negative effects of SA on plant growth and development. Similarly, auxin/IAA, which is also known to regulate plant growth and development (Gallei et al. 2020), have been negatively correlated with SA based defenses (Wang et al. 2007; Koo et al. 2020; Tan et al. 2020). We also found higher basal IAA levels in 14 day SCA-uninfested SC35 plants and lower SA levels in SCA-infested SC35 plants compared to RTx 430 and SC1345 plants 7 dpi (Figs. 3d and 4a). Similarly, SA levels were significantly lower in SCA-infested SC35 plants compared to RTx430 plants 14 dpi (Fig. 3d). Additional work is needed to determine how crosstalk between IAA and SA contribute to sorghum tolerance to aphids.

CKs, another category of phytohormones, play an important role in regulation of plant growth and stabilization of photosynthetic machinery during stress (Werner et al. 2001; Gururani et al. 2015; Prerostova et al. 2018). Furthermore, CKs are also known to delay leaf senescence and improve plant tolerance to heat stress (Xu and Huang 2009). Interestingly, CKs have also been identified in several phytophagous 
insects, including aphids (Andreas et al. 2020). Our data demonstrate that the SCA feeding for 7 days induced comparable levels of tZR in both RTx430 and SC35 plants, but was not detectable in the aphid susceptible SC1345 sorghum plants. Furthermore, tZR accumulation was more pronounced in SC35 tolerant genotype compared with RTx430 plants after 14 days of SCA infestation (Fig. 5a). SCA feeding also significantly enhanced the accumulation of cZR, the less active form of zeatin (Großkinsky et al. 2013), in SC35 tolerant genotype and was comparable to RTx430 plants after $14 \mathrm{dpi}$ (Fig. 5b). One possible explanation is that upon aphid infestation plants activate CKs to promote plant growth and photosynthesis in the aphid-tolerant sorghum genotype. tZR is synthesized in roots and translocated to shoot via xylem vessels and is reported to play an important role in plant growth (Osugi et al. 2017). Foliar feeding by SCA may trigger the synthesis of tZR in roots and transported to the shoot through the vascular tissues to provide sorghum tolerance to aphids. In fact, we have previously shown that aboveground to belowground (and vice-versa) signaling interactions in the resistant maize genotype act as a critical component in modulating maize resistance to corn leaf aphids (Louis et al. 2015). Alternatively, CKs injected into the plants by aphids while feeding could alter source-sink mechanisms to enhance sustained feeding and facilitate aphid colonization on host plants. However, the latter hypothesis is undercut by the observation that susceptible sorghum plants did not accumulate tZR in response to SCA infestation. It is highly plausible that aphids utilize ABA in susceptible plants (Studham and MacIntosh 2012; Hillwig et al. 2016; Chapman et al. 2018), whereas aphids exploit CKs in tolerant plants for their successful colonization. Although the origin and source of CKs remains to be determined, the accumulation of CKs in the aphid-tolerant sorghum genotype is consistent with its prospective role in providing sorghum tolerance to aphids.

In summary, we provide evidence that the interplay of phytohormones contribute to plant tolerance to aphids. Plants utilize the interactions among diverse signaling pathways to facilitate improved plant growth and development. Our results provide important clues to how these unknown and underappreciated tolerance mechanisms influence the development of novel and durable pest management strategies. Plant resistance to insects is frequently controlled by quantitatively inherited traits (Smith 2005; Zogli et al. 2020). It is highly likely that plant tolerance is also governed by quantitative trait loci (QTL), because of its complex nature. This and other possible components/mechanisms of plant tolerance to aphids will be further dissected out in our future work.

Acknowledgements We would like to acknowledge Manny Saluja and John Toy for help with LI-COR data measurements and seed production, respectively. We also thank Harkamal Walia and Tala Awada for providing access to LI-COR instrument, Emily Robinson with statistical analysis, and the Proteomic and Metabolomics Facility (Center for Biotechnology at the University of Nebraska-Lincoln) for the LC-MS assay and quantification of plant hormones.

Author contributions SG and JL conceived and designed the research; SG and EA performed the research; GS and SES contributed reagents, methods development and provided guidance on experiments; SG and JL wrote the paper. All authors reviewed and edited the manuscript.

Funding Work in the Louis laboratory was supported by funds from US National Science Foundation CAREER grant IOS-1845588 and USDA-ARS (58-3042-6-070). This work was partially supported by USDA-ARS CRIS projects 3042-21000-034-00-D (GS) and 304221220-033-00-D (SES). E.A. was partly supported by Undergraduate Creative Activity and Research (UCARE) and Agricultural Research Division (ARD) Undergraduate Student Research funds from the University of Nebraska-Lincoln.

\section{Compliance with ethical standards}

Conflict of interest The authors have no conflicts of interest to declare.

\section{References}

Andreas P, Kisiala A, Emery RJN, De Clerck-Floate R, Tooker JF, Price PW, Miller DG, Chen M-S, Connor EF (2020) Cytokinins are abundant and widespread among insect species. Plants 9:208. https://doi.org/10.3390/plants9020208

Armstrong JS, Rooney WL, Peterson GC, Villenueva RT, Brewer MJ, Sekula-Ortiz D (2015) Sugarcane aphid (Hemiptera: Aphididae): host range and sorghum resistance including cross-resistance from greenbug sources. J Econ Entomol 108:576-582. https:// doi.org/10.1093/jee/tou065

Armstrong JS, Paudyal S, Limaje A, Elliott N, Hoback W (2018) Plant resistance in sorghums to the sugarcane aphid (Hemiptera: Aphididae). J Entomol Sci 53:478-485. https://doi.org/10.18474 /JES17-106.1

Barbosa dos Santos I, Park S-W (2019) Versatility of cyclophilins in plant growth and survival: a case study in Arabidopsis. Biomolecules. https://doi.org/10.3390/biom9010020

Beck SD (1965) Resistance of plants to insects. Annu Rev Entomol 10:207-232. https://doi.org/10.1146/annurev.en.10.010165.00123 1

Bouchet S, Olatoye MO, Marla SR, Perumal R, Tesso T, Yu J, Tuinstra M, Morris GP (2017) Increased power to dissect adaptive traits in global sorghum diversity using a nested association mapping population. Genetics 206:573-585. https://doi.org/10.1534/genet ics.116.198499

Bowling RD, Brewer MJ, Kerns DL, Gordy J, Seiter N, Elliott NE, Buntin GD, Way MO, Royer TA, Biles S, Maxson E (2016) Sugarcane aphid (Hemiptera: Aphididae): a new pest on sorghum in North America. J Integr Pest Manag. https://doi.org/10.1093/ jipm/pmw011

Chapman KM, Marchi-Werle L, Hunt TE, Heng-Moss TM, Louis J (2018) Abscisic and jasmonic acids contribute to soybean tolerance to the soybean aphid (Aphis glycines Matsumura). Sci Rep 8:1-12. https://doi.org/10.1038/s41598-018-33477-w

de Morais CL, Pinheiro SS, Martino HSD, Pinheiro-Sant'Ana HM (2017) Sorghum (Sorghum bicolor L.): nutrients, bioactive 
compounds, and potential impact on human health. Crit Rev Food Sci Nutr 57:372-390. https://doi.org/10.1080/10408 398.2014.887057

Erb M, Meldau S, Howe GA (2012) Role of phytohormones in insectspecific plant reactions. Trends Plant Sci 17:250-259. https://doi. org/10.1016/j.tplants.2012.01.003

Foyer CH, Noctor G (2005) Redox homeostasis and antioxidant signaling: a metabolic interface between stress perception and physiological responses. Plant Cell 17:1866-1875. https://doi. org/10.1105/tpc. 105.033589

Gallei M, Luschnig C, Friml J (2020) Auxin signalling in growth: Schrödinger's cat out of the bag. Curr Opin Plant Biol 53:43-49. https://doi.org/10.1016/j.pbi.2019.10.003

González-Lamothe R, El Oirdi M, Brisson N, Bouarab K (2012) The conjugated auxin indole-3-acetic acid-aspartic acid promotes plant disease development. Plant Cell 24:762-777. https://doi. org/10.1105/tpc.111.095190

Großkinsky DK, Edelsbrunner K, Pfeifhofer H, van der Graaff E, Roitsch T (2013) Cis- and trans-zeatin differentially modulate plant immunity. Plant Signal Behav 8:e24798. https://doi.org/10.4161/ psb. 24798

Grover S, Varsani S, Kolomiets MV, Louis J (2020) Maize defense elicitor, 12-oxo-phytodienoic acid, prolongs aphid salivation. Commun Integr Biol 13:63-66. https://doi.org/10.1080/19420 889.2020.1763562

Gururani MA, Mohanta TK, Bae H (2015) Current understanding of the interplay between phytohormones and photosynthesis under environmental stress. Int J Mol Sci 16:19055-19085. https://doi. org/10.3390/ijms160819055

Hillwig MS, Chiozza M, Casteel CL, Lau ST, Hohenstein J, Hernández E, Jander G, MacIntosh GC (2016) Abscisic acid deficiency increases defence responses against Myzus persicae in Arabidopsis. Mol Plant Pathol 17:225-235. https://doi.org/10.1111/ mpp. 12274

Howe GA, Jander G (2008) Plant immunity to insect herbivores. Annu Rev Plant Biol 59:41-66. https://doi.org/10.1146/annurev.arpla nt.59.032607.092825

Hui D, Iqbal J, Lehmann K, Gase K, Saluz HP, Baldwin IT (2003) Molecular interactions between the specialist herbivore Manduca sexta (Lepidoptera, Sphingidae) and its natural host Nicotiana attenuata: microarray analysis and further characterization of large-scale changes in herbivore-induced mRNAs. Plant Physiol 131:1877-1893. https://doi.org/10.1104/pp.102.018176

Kerchev PI, Fenton B, Foyer CH, Hancock RD (2012) Plant responses to insect herbivory: interactions between photosynthesis, reactive oxygen species and hormonal signalling pathways. Plant Cell Environ 35:441-453. https://doi.org/10.111 1/j.1365-3040.2011.02399.x

Kiani M, Szczepaniec A (2018) Effects of sugarcane aphid herbivory on transcriptional responses of resistant and susceptible sorghum. BMC Genomics 19:774. https://doi.org/10.1186/s1286 4-018-5095-x

Koch KG, Chapman K, Louis J, Heng-Moss T, Sarath G (2016) Plant tolerance: a unique approach to control hemipteran pests. Front Plant Sci. https://doi.org/10.3389/fpls.2016.01363

Koo YM, Heo AY, Choi HW (2020) Salicylic acid as a safe plant protector and growth regulator. Plant Pathol J 36:1-10. https://doi. org/10.5423/ppj.rw.12.2019.0295

Kopriva S (2013) 12-Oxo-phytodienoic acid interaction with cyclophilin CYP20-3 is a benchmark for understanding retrograde signaling in plants. Proc Natl Acad Sci USA 110:9197-9198. https:// doi.org/10.1073/pnas.1307482110

Kotchoni SO, Gachomo EW (2006) The reactive oxygen species network pathways: an essential prerequisite for perception of pathogen attack and the acquired disease resistance in plants. J Biosci 31:389-404. https://doi.org/10.1007/BF02704112
Li S, Zhao J, Zhai Y, Yuan Q, Zhang H, Wu X, Lu Y, Peng J, Sun Z, Lin L, Zheng H, Chen J, Yan F (2019) The hypersensitive induced reaction 3 (HIR3) gene contributes to plant basal resistance via an EDS1 and salicylic acid-dependent pathway. Plant J 98:783-797. https://doi.org/10.1111/tpj.14271

Liu X, Williams CE, Nemacheck JA, Wang H, Subramanyam S, Zheng C, Chen M-S (2010) Reactive oxygen species are involved in plant defense against a gall midge. Plant Physiol 152:985-999. https:// doi.org/10.1104/pp.109.150656

Louis J, Shah J (2013) Arabidopsis thaliana-Myzus persicae interaction: shaping the understanding of plant defense against phloem-feeding aphids. Front Plant Sci. https://doi.org/10.3389/ fpls.2013.00213

Louis J, Basu S, Varsani S, Castano-Duque L, Jiang V, Williams WP, Felton GW, Luthe DS (2015) Ethylene contributes to maize insect resistance 1 -mediated maize defense against the phloem sapsucking corn leaf aphid. Plant Physiol 169:313-324. https://doi. org/10.1104/pp.15.00958

Machado RAR, Arce CCM, Ferrieri AP, Baldwin IT, Erb M (2015) Jasmonate-dependent depletion of soluble sugars compromises plant resistance to Manduca sexta. New Phytol 207:91-105. https ://doi.org/10.1111/nph.13337

Mapes CC, Davies PJ (2001) Cytokinins in the ball gall of Solidago altissima and in the gall forming larvae of Eurosta solidaginis. New Phytol 151:203-212. https://doi.org/10.104 6/j.1469-8137.2001.00158.x

Moran PJ, Cheng Y, Cassell JL, Thompson GA (2002) Gene expression profiling of Arabidopsis thaliana in compatible plant-aphid interactions. Arch Insect Biochem Physiol 51:182-203. https:// doi.org/10.1002/arch.10064

Nalam V, Louis J, Shah J (2019) Plant defense against aphids, the pest extraordinaire. Plant Sci 279:96-107. https://doi.org/10.1016/j. plantsci.2018.04.027

Negin B, Yaaran A, Kelly G, Zait Y, Moshelion M (2019) Mesophyll abscisic acid restrains early growth and flowering but does not directly suppress photosynthesis. Plant Physiol 180:910-925. https://doi.org/10.1104/pp.18.01334

Nibouche S, Costet L, Holt JR, Jacobson A, Pekarcik A, Sadeyen J, Armstrong JS, Peterson GC, McLaren N, Medina RF (2018) Invasion of sorghum in the Americas by a new sugarcane aphid (Melanaphis sacchari) superclone. PLoS ONE. https://doi.org/10.1371/ journal.pone.0196124

Osugi A, Kojima M, Takebayashi Y, Ueda N, Kiba T, Sakakibara H (2017) Systemic transport of trans-zeatin and its precursor have differing roles in Arabidopsis shoots. Nat Plants 3:1-6. https://doi. org/10.1038/nplants.2017.112

Painter RH (1951) Insect resistance in crop plants. Macmillan, New York

Panda N, Khush GA (1995) Host plant resistance to insects. CAB International, Wallingford

Peterson RKD, Varella AC, Higley LG (2017) Tolerance: the forgotten child of plant resistance. PeerJ 5:e3934. https://doi.org/10.7717/ peerj. 3934

Prerostova S, Dobrev PI, Gaudinova A, Knirsch V, Körber N, Pieruschka R, Fiorani F, Brzobohatý B, Černý M, Spichal L, Humplik J, Vanek T, Schurr U, Vankova R (2018) Cytokinins: their impact on molecular and growth responses to drought stress and recovery in Arabidopsis. Front Plant Sci. https://doi. org/10.3389/fpls.2018.00655

Singh V, Louis J, Ayre BG, Reese JC, Shah J (2011) TREHALOSE PHOSPHATE SYNTHASE11-dependent trehalose metabolism promotes Arabidopsis thaliana defense against the phloemfeeding insect Myzus persicae. Plant J 67:94-104. https://doi. org/10.1111/j.1365-313X.2011.04583.x

Smith CM (2005) Plant resistance to arthropods: molecular and conventional approaches. Springer, Dordrecht 
Studham ME, MacIntosh GC (2012) Multiple phytohormone signals control the transcriptional response to soybean aphid infestation in susceptible and resistant soybean plants. Mol Plant Microbe Interact 26:116-129. https://doi.org/10.1094/MPMI-05-12-0124-FI

Tan S, Abas M, Verstraeten I, Glanc M, Molnár G, Hajný J, Lasák P, Petř́k I, Russinova E, Petrášek J, Novák O, Pospíšil J, Friml J (2020) Salicylic acid targets protein phosphatase 2A to attenuate growth in plants. Curr Biol 30:381-395.e8. https://doi. org/10.1016/j.cub.2019.11.058

Tetreault HM, Grover S, Scully ED, Gries T, Palmer NA, Sarath G, Louis J, Sattler SE (2019) Global responses of resistant and susceptible sorghum (Sorghum bicolor) to sugarcane aphid (Melanaphis sacchari). Front Plant Sci 10:145. https://doi.org/10.3389/ fpls.2019.00145

Tooker JF, De Moraes CM (2011) Feeding by a gall-inducing caterpillar species alters levels of indole-3-acetic and abscisic acid in Solidago altissima (Asteraceae) stems. Arthropod-Plant Interact 5:115-124. https://doi.org/10.1007/s11829-010-9120-5

van Butselaar T, Van den Ackerveken G (2020) Salicylic acid steers the growth-immunity tradeoff. Trends Plant Sci. https://doi. org/10.1016/j.tplants.2020.02.002

Vanderlip RL, Reeves HE (1972) Growth stages of sorghum [Sorghum bicolor, (L.) Moench.]. Agron J 64:13-16. https://doi.org/10.2134/ agronj1972.00021962006400010005x

Varsani S, Grover S, Zhou S, Koch KG, Huang P-C, Kolomiets MV, Williams WP, Heng-Moss T, Sarath G, Luthe DS, Jander G, Louis J (2019) 12-Oxo-phytodienoic acid acts as a regulator of maize defense against corn leaf aphid. Plant Physiol. https://doi. org/10.1104/pp.18.01472

Verma V, Ravindran P, Kumar PP (2016) Plant hormone-mediated regulation of stress responses. BMC Plant Biol 16:86. https://doi. org/10.1186/s12870-016-0771-y

Voothuluru P, Meng J, Khajuria C, Louis J, Zhu L, Starkey S, Wilde GE, Baker CA, Smith CM (2006) Categories and inheritance of resistance to Russian wheat aphid (Homoptera: Aphididae) Biotype 2 in a selection from wheat cereal introduction 2401. J Econ Entomol 99:1854-1861. https://doi.org/10.1603/0022-0493-99.5.1854

Wang D, Pajerowska-Mukhtar K, Culler AH, Dong X (2007) Salicylic acid inhibits pathogen growth in plants through repression of the auxin signaling pathway. Curr Biol 17:1784-1790. https://doi. org/10.1016/j.cub.2007.09.025
Wasternack C, Strnad M (2018) Jasmonates: news on occurrence, biosynthesis, metabolism and action of an ancient group of signaling compounds. Int J Mol Sci. https://doi.org/10.3390/ijms19092539

Werner T, Motyka V, Strnad M, Schmülling T (2001) Regulation of plant growth by cytokinin. Proc Natl Acad Sci USA 98:1048710492. https://doi.org/10.1073/pnas. 171304098

White WH, Reagan TE, Hall DG (2001) Melanaphis sacchari (Homoptera: Aphididae), A sugarcane pest new to Louisiana. Fla Entomol 435

Xu Y, Huang B (2009) Effects of foliar-applied ethylene inhibitor and synthetic cytokinin on creeping bentgrass to enhance heat tolerance. Crop Sci 49:1876-1884. https://doi.org/10.2135/cropsci200 8.07.0441

Ym K, Ay H, Hw C (2020) Salicylic acid as a safe plant protector and growth regulator. Plant Pathol J 36:1-10. https://doi.org/10.5423/ ppj.rw.12.2019.0295

Yoshida T, Christmann A, Yamaguchi-Shinozaki K, Grill E, Fernie AR (2019) Revisiting the basal role of ABA-roles outside of stress. Trends Plant Sci 24:625-635. https://doi.org/10.1016/j. tplants.2019.04.008

Zhang N, Zhou S, Yang D, Fan Z (2020) Revealing shared and distinct genes responding to JA and SA signaling in Arabidopsis by metaanalysis. Front Plant Sci. https://doi.org/10.3389/fpls.2020.00908

Zhu-Salzman K, Salzman RA, Ahn J-E, Koiwa H (2004) Transcriptional regulation of sorghum defense determinants against a phloem-feeding aphid. Plant Physiol 134:420-431. https://doi. org/10.1104/pp.103.028324

Zogli P, Pingault L, Grover S, Louis J (2020) Ento(o)mics: the intersection of "omic" approaches to decipher plant defense against sap-sucking insect pests. Curr Opin Plant Biol 56:153-161. https ://doi.org/10.1016/j.pbi.2020.06.002

Züst T, Agrawal AA (2016) Mechanisms and evolution of plant resistance to aphids. Nat Plants 2:1-9. https://doi.org/10.1038/nplan ts. 2015.206

Publisher's Note Springer Nature remains neutral with regard to jurisdictional claims in published maps and institutional affiliations. 


\section{Supplemental Information}

\section{Interplay of phytohormones facilitate sorghum tolerance to aphids}

Sajjan Grover ${ }^{1}$, Earl Agpawa ${ }^{1}$, Gautam Sarath ${ }^{2}$, Scott E. Sattler ${ }^{2}$, and Joe Louis ${ }^{1,3, *}$

${ }^{1}$ Department of Entomology and ${ }^{3}$ Department of Biochemistry, University of Nebraska-Lincoln, Lincoln, NE 68583

${ }^{2}$ Wheat, Sorghum, and Forage Research Unit, USDA-ARS, Lincoln, NE 68583

*Author for Correspondence: Joe Louis

Department of Entomology and Department of Biochemistry University of Nebraska-Lincoln, Lincoln, NE 68583, USA

E-mail: joelouis@unl.edu; Phone: (402) 472-8098 


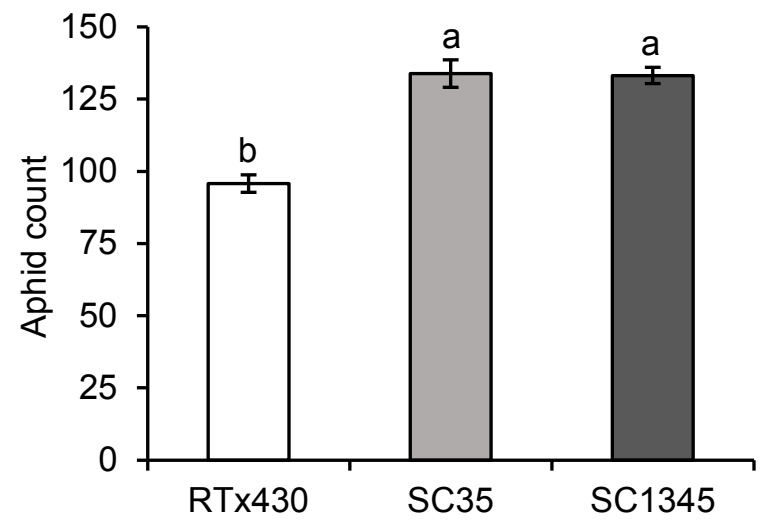

Supp. Fig. S1. Total number of sugarcane aphids recovered seven days after aphid infestation of two-weekold sorghum RTx430, SC35, and SC1345 plants that were initially infested with 10 adult apterous aphids per plant. $(n=12)$. Negative binomial distribution was used to analyze aphid count data. Different letters indicate significant differences among genotypes $(P<0.05$; Tukey's test). Error bars represent mean $\pm \mathrm{SE}$. 


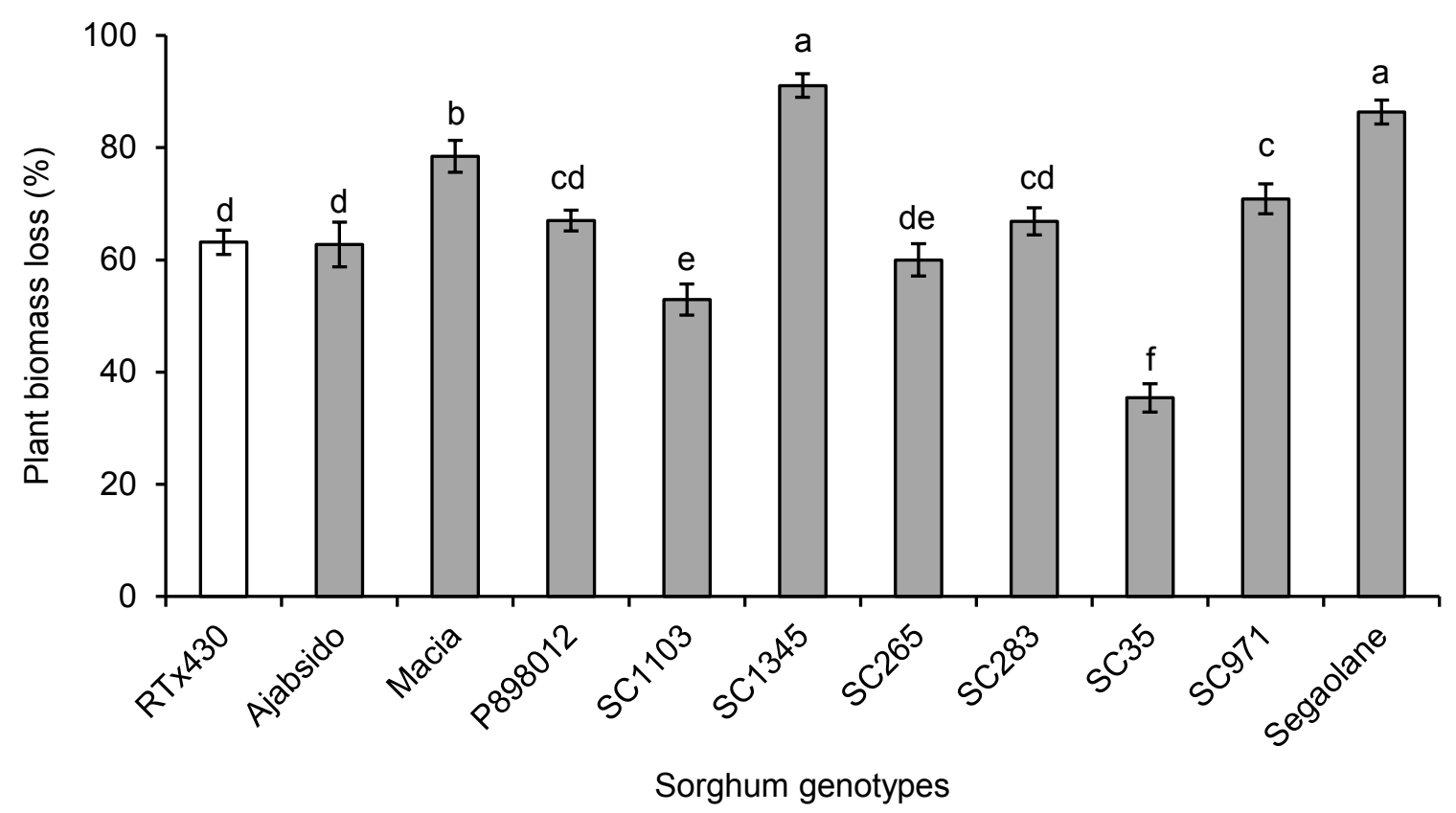

Supp. Fig. S2. Percent plant biomass loss for each sorghum NAM founder line after 14 days of sugarcane aphid (SCA) infestation of two-week-old sorghum plants that were initially infested with 10 adult apterous aphids per plant. Uninfested plants of similar age were used as controls to calculate changes in plant biomass upon aphid infestation $(n=12)$. Different letters indicate significant differences among genotypes $(P<0.05$; Tukey's test). Error bars represent mean \pm SE. 
a

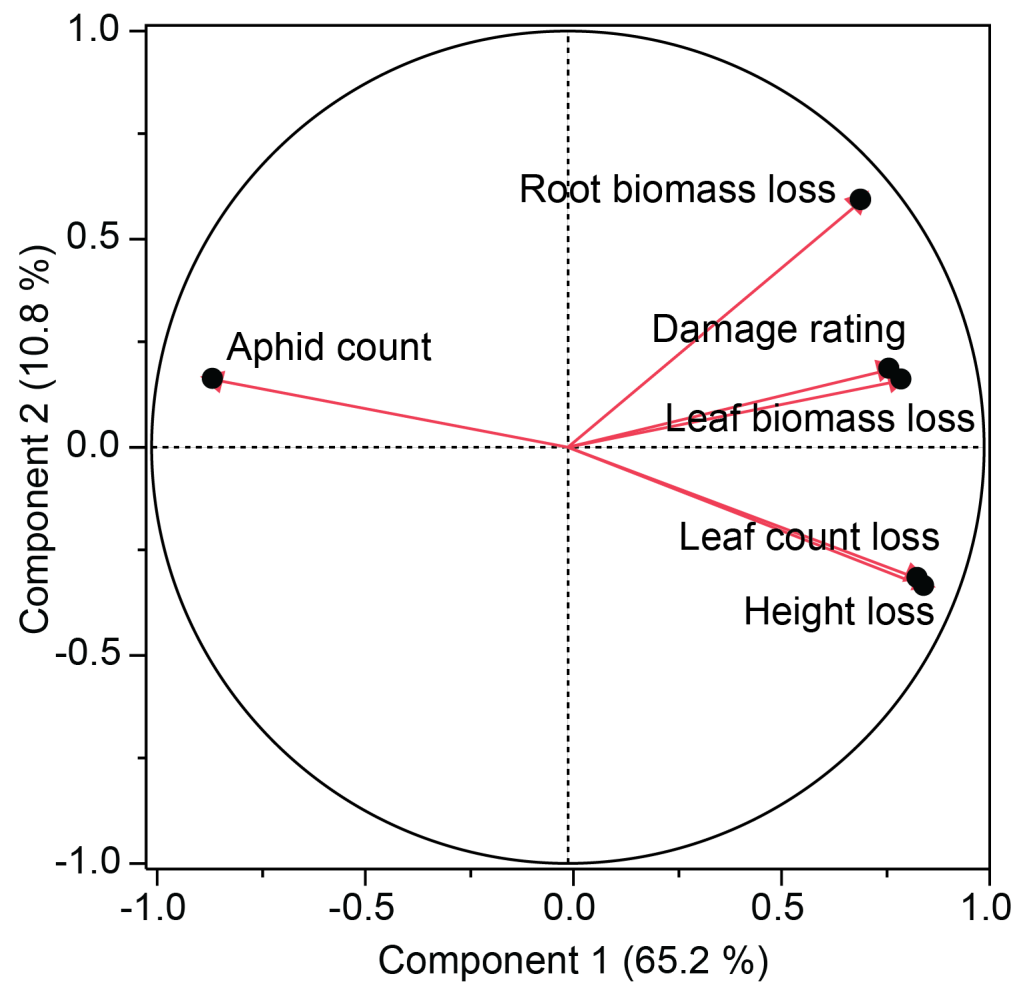

b

\begin{tabular}{|c|c|c|c|c|c|c|}
\hline & Prin1 & Prin2 & Prin3 & Prin4 & Prin5 & Prin6 \\
\hline Aphid count & -0.8508 & 0.16223 & 0.25757 & 0.09762 & 0.36602 & 0.19996 \\
\hline Leaf biomass loss & 0.80333 & 0.16071 & 0.10652 & -0.54692 & 0.10953 & 0.07979 \\
\hline Root biomass loss & 0.70601 & 0.59212 & -0.31384 & 0.20261 & 0.10679 & 0.00134 \\
\hline Leaf count loss & 0.84208 & -0.31603 & 0.05929 & 0.11512 & 0.35949 & -0.21218 \\
\hline Height loss & 0.85781 & -0.33519 & -0.13295 & 0.14691 & -0.01973 & 0.33491 \\
\hline Damage rating & 0.7742 & 0.18669 & 0.54153 & 0.20203 & -0.17795 & -0.00457 \\
\hline
\end{tabular}

Supp. Fig. S3. (A) Loading plot of principal components 1 and 2 from the principal component analysis (PCA) of data collected from tolerance experiment on sorghum NAM founder lines after 14 days of SCA infestation. The loading data depicts the unrotated loading matrix between the variables and the components. Uninfested plants of similar age were used to calculate changes in plant growth upon aphid infestation. (B) Loading data of the PCA that indicates the effects of components on different variables. 


\section{Supplementary Table S1}

Total number of sugarcane aphids recovered 14 days after aphid infestation of two-week-old sorghum plants that were initially infested with 10 adult apterous aphids per plant.

\begin{tabular}{|c|c|}
\hline Genotype & $\begin{array}{c}\text { Aphid numbers } \\
\text { (Mean } \pm \text { SE) }\end{array}$ \\
\hline RTx430 & $399.58 \pm 25.82 \mathrm{~cd}$ \\
\hline Ajabsido & $552.33 \pm 34.5 \mathrm{~b}$ \\
\hline Macia & $249.6 \pm 63.83 \mathrm{fg}$ \\
\hline P898012 & $501.08 \pm 31.7 \mathrm{bc}$ \\
\hline SC1103 & $673.75 \pm 46 \mathrm{a}$ \\
\hline SC1345 & ----- \\
\hline SC265 & $217.83 \pm 21.99 \mathrm{ef}$ \\
\hline SC283 & $378.11 \pm 26.75 \mathrm{de}$ \\
\hline SC35 & $724.75 \pm 43.68 \mathrm{a}$ \\
\hline SC971 & $409.33 \pm 39.91 \mathrm{ef}$ \\
\hline Segaolane & $255.33 \pm 53.36 \mathrm{~g}$ \\
\hline
\end{tabular}

Negative binomial distribution was used to analyze aphid count data. Different letters indicate significant difference relative to each other $(P<0.05$; Tukey's test). Values in table represent mean $\pm \operatorname{SE}(n=12)$. The susceptible SC1345 plants were dead by 14 dpi as a result of SCA feeding; consequently, no live aphids were found on SCA-susceptible sorghum SC1345 plants. 


\section{Supplementary Table S2}

Plant growth parameters of sorghum genotypes with and without sugarcane aphid infestation for 14 days.

\begin{tabular}{|c|c|c|c|c|c|c|c|c|}
\hline \multirow{2}{*}{ Genotypes } & \multicolumn{2}{|c|}{ Height (cm) } & \multicolumn{2}{c|}{ Leaf count (number) } & \multicolumn{2}{c|}{ Leaf biomass (mg) } & \multicolumn{2}{c|}{ Root Biomass (mg) } \\
\cline { 2 - 8 } & Uninfested & Infested & Uninfested & Infested & Uninfested & Infested & Uninfested & Infested \\
\hline RTx430 & $49.81 \pm 1.60$ & $32.94 \pm 2.24$ & $5.33 \pm 0.14$ & $4.00 \pm 0.21$ & $277.58 \pm 15.10$ & $100.92 \pm 7.85$ & $70.5 \pm 4.59$ & $27.33 \pm 2.27$ \\
\hline Ajabsido & $50.53 \pm 1.23$ & $37.12 \pm 1.55$ & $6.00 \pm 0.00$ & $3.75 \pm 0.18$ & $299.08 \pm 9.87$ & $111.75 \pm 12.97$ & $75.08 \pm 4.24$ & $27.67 \pm 3.32$ \\
\hline Macia & $44.21 \pm 0.45$ & $29.4 \pm 1.90$ & $5.00 \pm 0.00$ & $1.17 \pm 0.42$ & $203.17 \pm 7.74$ & $61.11 \pm 3.70$ & $81.42 \pm 6.52$ & $15.42 \pm 1.79$ \\
\hline P898012 & $57.52 \pm 0.68$ & $35.98 \pm 1.60$ & $5.75 \pm 0.13$ & $3.58 \pm 0.23$ & $326.92 \pm 12.72$ & $112.33 \pm 7.48$ & $101.08 \pm 6.94$ & $28.92 \pm 3.37$ \\
\hline SC1103 & $46.75 \pm 0.94$ & $34.14 \pm 1.44$ & $6.00 \pm 0.00$ & $4.00 \pm 0.21$ & $277.17 \pm 15.99$ & $139.17 \pm 9.68$ & $102.25 \pm 7.04$ & $39.42 \pm 2.04$ \\
\hline SC1345 & $53.43 \pm 1.23$ & $31.52 \pm 2.18$ & $5.00 \pm 0.12$ & ---- & $327.08 \pm 31.56$ & $56 \pm 2.76$ & $73.33 \pm 7.53$ & $12.42 \pm 1.70$ \\
\hline SC265 & $39.7 \pm 1.07$ & $22.93 \pm 1.33$ & $5.00 \pm 0.00$ & $3.75 \pm 0.13$ & $124.25 \pm 8.72$ & $52.33 \pm 3.61$ & $38.42 \pm 2.41$ & $12.75 \pm 1.70$ \\
\hline SC283 & $43.41 \pm 0.82$ & $28.88 \pm 1.72$ & $5.00 \pm 0.00$ & $2.42 \pm 0.43$ & $197.75 \pm 7.29$ & $60.92 \pm 7.19$ & $61.75 \pm 4.48$ & $25.08 \pm 3.30$ \\
\hline SC35 & $57.75 \pm 1.08$ & $49.18 \pm 1.43$ & $5.67 \pm 0.14$ & $4.83 \pm 0.11$ & $352.67 \pm 11.63$ & $238.25 \pm 10.23$ & $107.33 \pm 3.94$ & $58.83 \pm 3.20$ \\
\hline SC971 & $48.38 \pm 0.96$ & $33.45 \pm 2.29$ & $5.00 \pm 0.00$ & $1.50 \pm 0.48$ & $257.58 \pm 9.68$ & $80.92 \pm 8.74$ & $74.42 \pm 4.41$ & $15.83 \pm 2.27$ \\
\hline Segaolane & $49.61 \pm 0.90$ & $17.47 \pm 0.82$ & $4.75 \pm 0.13$ & $0.67 \pm 0.36$ & $218.75 \pm 11.10$ & $41.67 \pm 4.51$ & $62.08 \pm 3.84$ & $7.08 \pm 1.43$ \\
\hline
\end{tabular}

Two-week-old sorghum nested association mapping (NAM) founder lines were initially infested with 10 adult apterous aphids per plant and various plant growth parameters monitored after 14 days post infestation. Uninfested plants were used as controls. Values in table represent mean $\pm \mathrm{SE}(n=12)$. 